\title{
Experimental Investigation of Rotor-Stator Interaction in Axial-Flow Turbines and Compressors*
}

\author{
HEINZ E. GALLUS ${ }^{\dagger}$ \\ Institut für Strahlantriebe und Turboarbeitsmaschinen, RWTH Aachen (Aachen University of Technology), \\ 52062 Aachen, Germany
}

(Received 3 April 1997; In final form 10 July 1997)

\begin{abstract}
Detailed results of unsteady flow measurements in a stator-rotor-stator assembly of an axial-flow turbine as well as an inlet guide vane-rotor-stator formation of an axial-flow compressor are presented in this paper.

The measurements include the time-dependent 3-D velocity vector fields in the axial gaps between the blade rows by means of triple-hot wire-technique, furthermore the total pressure field downstream of the blade rows by means of semiconductor total pressure probes and the unsteady flow field determination in the rotor passages by LDV-technique. Special semiconductor pressure measurements along the casing all over the rotor tip clearance permit detailed discussion of the rotor tip clearance flows.

The conclusion of the measured data provides a new and very instructive view of the physics of the unsteady blade-row interaction in axial-flow turbines and compressors.
\end{abstract}

Keywords: Experiments, Compressor flow, Turbine flow, Secondary effects, Periodic interaction

\section{INTRODUCTION}

Most of the present analysis and design methods in turbomachinery are based on steady aerodynamics, although it is well known that the unsteady flow associated with blade row interaction has a major influence on the flow field, boundary layers, turbulence intensities, flow separation, blade vibration, noise, and heat transfer. The demand for higher performance in aircraft as well as heavy duty gas turbine design results in a close axial spacing of the blade rows, lower aspect ratios and a reduced number of blades. This requires more sophisticated design methods, including the possibility to calibrate numerical methods and their turbulence modelling. There is a strong need to gain a better understanding of the three-dimensional unsteady flow in a blade row including the upstream and downstream influence of rotor-stator interactions.

Gallus et al. (1982) investigated the influence of blade number ratio and blade row spacing on axialflow compressor stator blade dynamic load and stagesound pressure level. By variation of the parameters blade number ratio and blade row spacing in

* This paper was originally presented at ISROMAC-6.

${ }^{\dagger}$ Fax: 0241-8888-229. 
an annular wind-tunnel they found experimentally as well as by numerical approaches the results shown in Figs. 1-3. Since the measurements and calculations were done for the midspan section these results are valid only for the flow at midspan.

Figure 1 shows the fluctuation of the local pressure coefficients compared with the local pneumatically measured mean values. The results reveal a much stronger increase of the dynamic pressure fluctuations with decreasing rotor-stator blade number ratio than with decreasing axial spacing $\Delta x / s$. Nevertheless, low blade number ratio $Z_{\mathrm{R}} / Z_{\mathrm{St}}$ and low axial spacing results in highest dynamic blade loads.

Figure 2 represents a comparison of the potentialtheoretic and the wake interactions as a function of the axial distance between the blade rows. It is obvious that the fluctuation amplitudes (plotted for the first harmonic) of the potential-theoretic interaction (computed after Lienhart, 1973) decrease
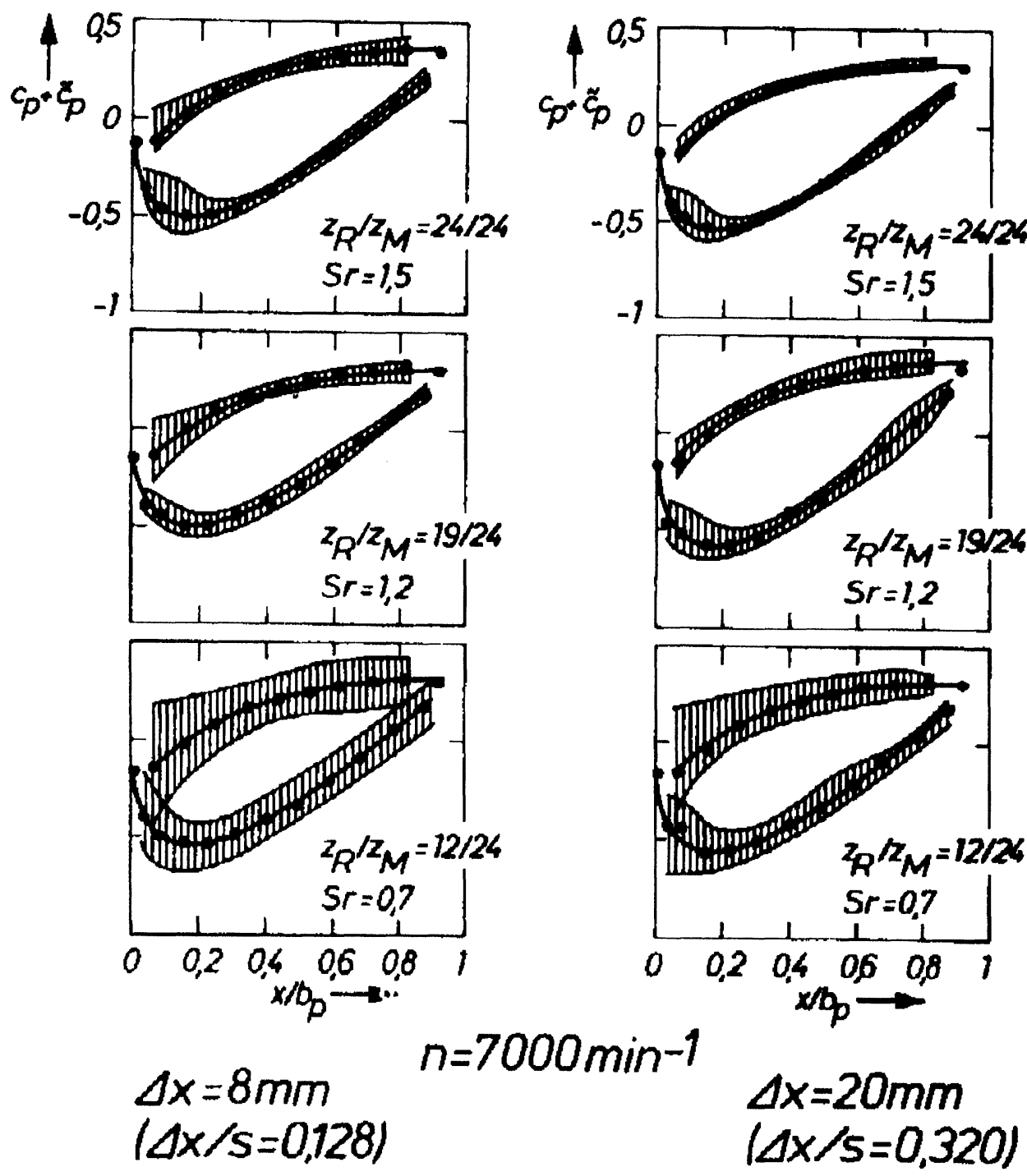

$n=7000 \min ^{-1}$

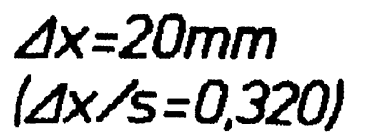

FIGURE 1 Fluctuation of the local pressure coefficients $c_{p}$, compared with the local mean values. 


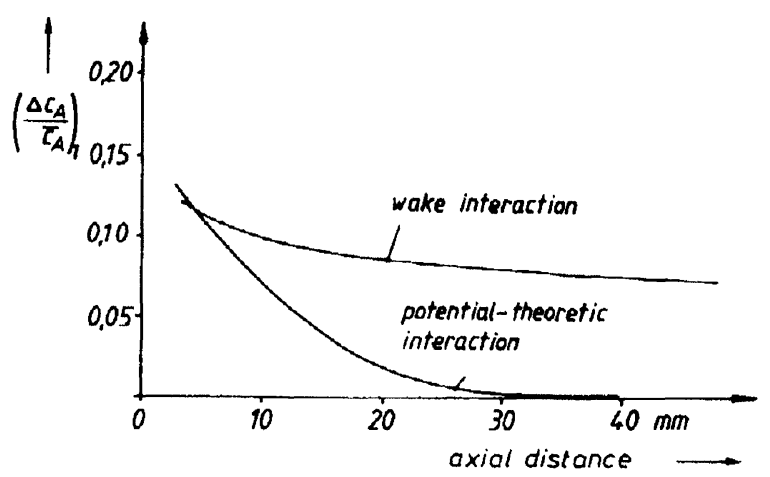

FIGURE 2 Comparison of the potential-theoretic and wake interactions as a function of the axial distances between the blade rows. more rapidly with increasing axial distance than the wake interaction amplitudes calculated according to Henderson (1972).

Figure 3 is also taken from Gallus et al. (1982) and compares computed and measured "stimuli" (representing dynamic blade forces to the static ones) as a function of the axial distance between the blade rows. The computed curves were gained by Lienhart's prediction method for the potentialtheoretic interaction alone. They show that the dynamic forces due to upstream interaction are higher than those due to downstream interaction. The experimental values measured only in the downstream blade row contain also the dynamic

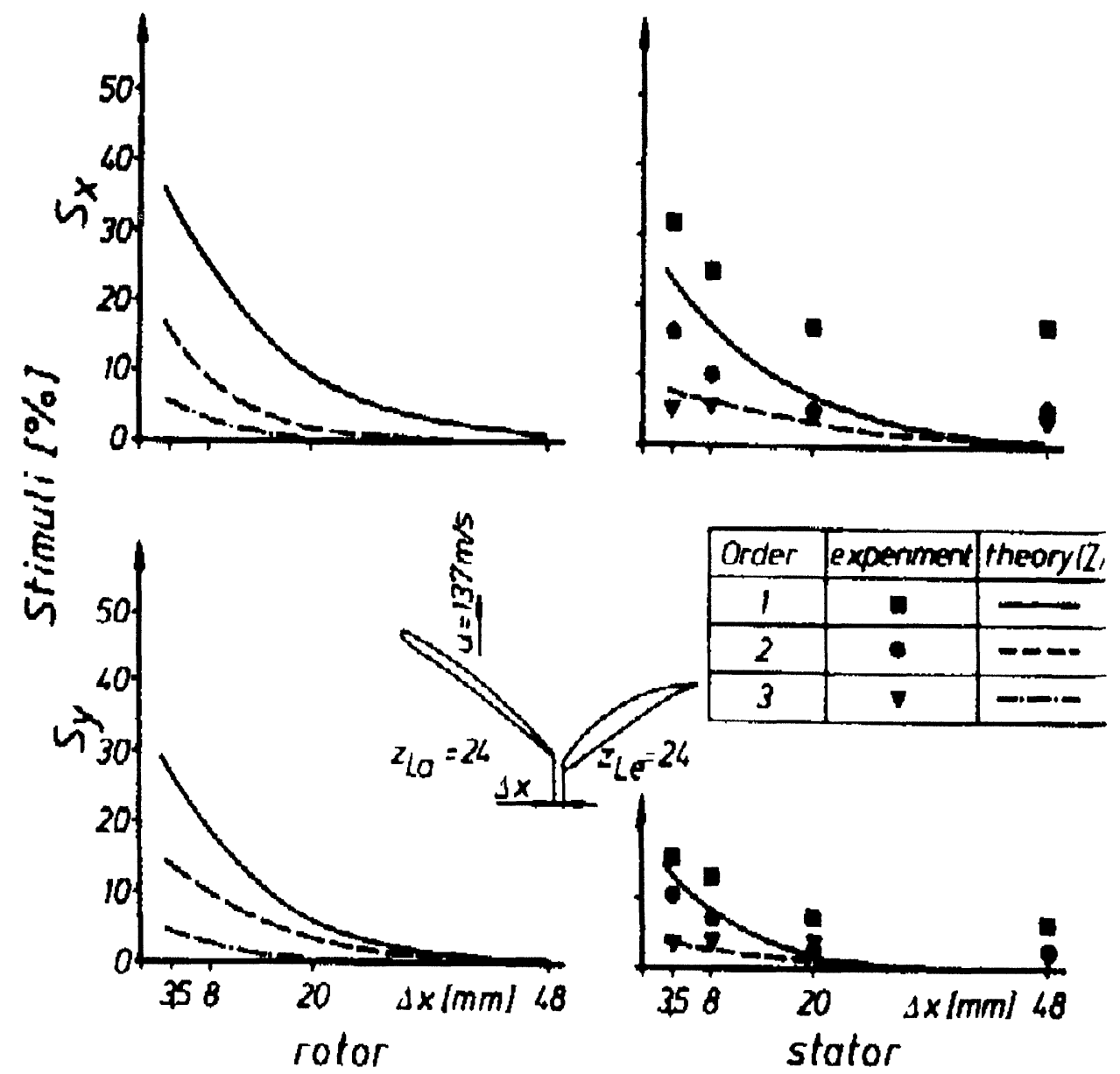

FIGURE 3 Computed and measured "stimuli" as a function of the axial distance between the blade rows. 
forces due to wake interaction and are much higher than the potential-theoretic results which is in good agreement with the information in Fig. 2.

For the design of bladings in axial-flow turbomachines these blade row interaction effects have to be considered. That means unsteady flow effects due to rotor-stator interactions do change the real flow compared with a pure steady design. For example, due to the fact that in the wakes of an axial-flow compressor rotor the exit flow angle fluctuates strongly in that way that the time-averaged incidence angle to the following stator is higher than that of the steady design for the core flow between the blades. That means, the wake effects in compressor blade rows result in a higher turning of the following blade row. It can easily be shown that the wakes in turbines reduce the time-averaged turning of the downstream blade row.

The above discussion of the rotor-stator interaction concerned at first the time-averaged loading of the blade rows. On the other hand, the profile pressure fluctuation due to rotor-stator interaction strongly influences the behaviour of profile as well as side wall boundary layers. The periodically fluctuating boundary layer behaviour leads do different positions of the onset and length of transition as well as boundary layer separation. These effects take strong influence on the losses and the efficiency, respectively. Investigations in annular cascades and real stages showed, that the flow through the blade passages and on the blade suction side surfaces is highly three-dimensional. That means midspan investigations are no longer representative for the blade row behaviour in a machine. That is why the investigations reported on in this paper were carried out measuring the flow field over the full span.

\section{EXPERIMENTAL INVESTIGATION OF THE THREE-DIMENSIONAL FLOW IN AN ANNULAR COMPRESSOR CASCADE}

The annular compressor stator cascade mentioned in the introduction was investigated with respect to the three-dimensional flow field at various incidence angles by Schulz and Gallus (1988). The inlet swirl was provided by variable inlet guide vanes far upstream of the stator cascade. Major objectives were the studies of corner stall and losses with increasing incidence angle. In order to check the influence of rotor-stator interaction on the 3-D flow field in the annular compressor cascade, Schulz et al. (1990) simulated the unsteady effects of a bladed rotor by using cylindrical spokes instead of blades. The swirl was further on provided by the variable inlet guide vanes in front. Figure 4 demonstrates the different boundary layer and corner stall behaviour on the blade suction surface with increasing incidence. The left column shows the oil-flow visualization on the blade suction side without rotor and in the right column with rotor. It becomes obvious, that due to the rotor-stator interaction the extent of the corner stall region has been extremely reduced. Figure 5 confirms these facts by a photo taken from the flow visualization on the hub surface. By total pressure measurements downstream of the annular cascade the authors found remarkable results about the loss behaviour. Figure 6 shows the loss distribution with increasing incidence. The left hand side demonstrates the circumferentially averaged losses at midspan, where the profile losses are dominating and side wall flow influences are comparatively small. In this case, the midspan losses are increased by rotor-stator interaction due to an earlier profile boundary layer transition. The right hand side of Fig. 6 shows the overall losses averaged circumferentially and from hub to tip as a function of incidence angle. In the whole incidence range the overall losses are lower due to rotor-stator interaction causing a higher turbulence level and stronger energy transport from the core flow to the low energy side wall flow.

It should be mentioned here, that these results of rotor-stator interaction on loss behaviour were achieved for an aspect ratio of only 0.86 explaining for the fact that the reduction of the overall losses by rotor-stator interaction is due to the strong loss reduction near the sidewalls that overcompensates 


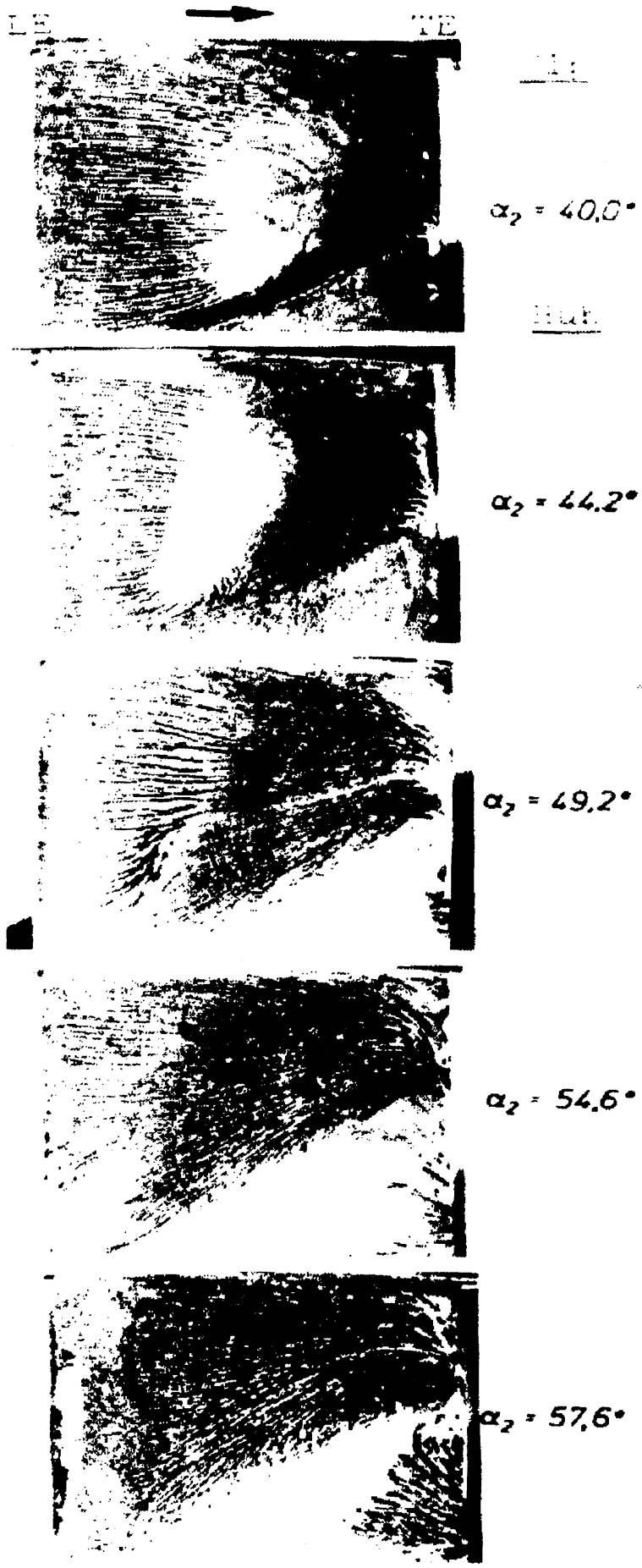

witrout rotor
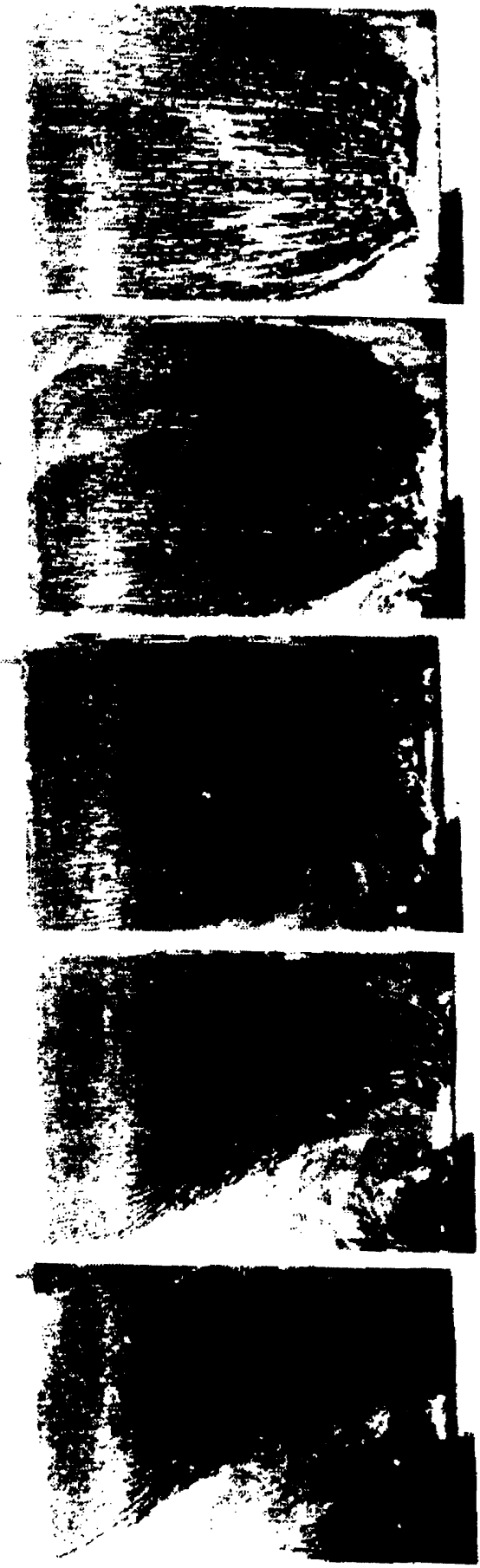

witin rotor

FIGURE 4 Oil flow visualization on the blade suction side. 


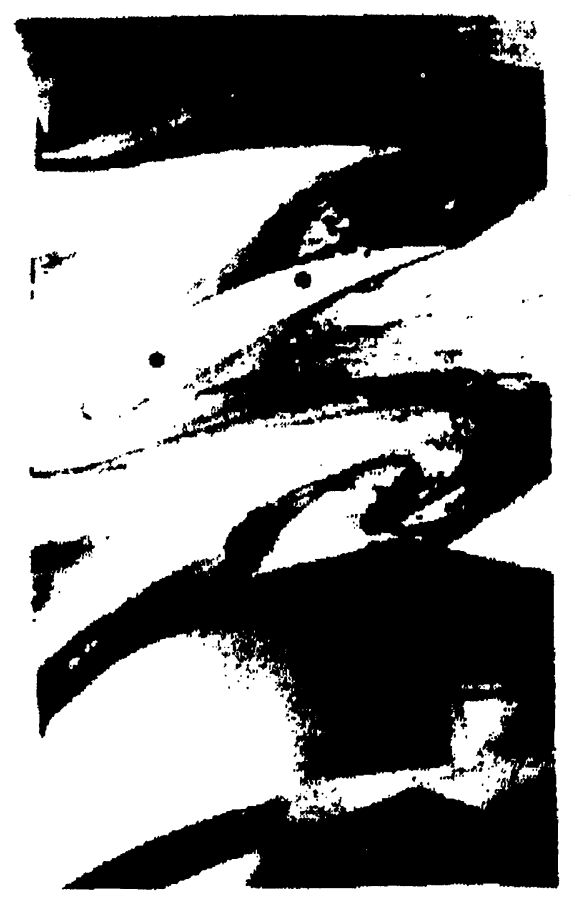

Without Rotor

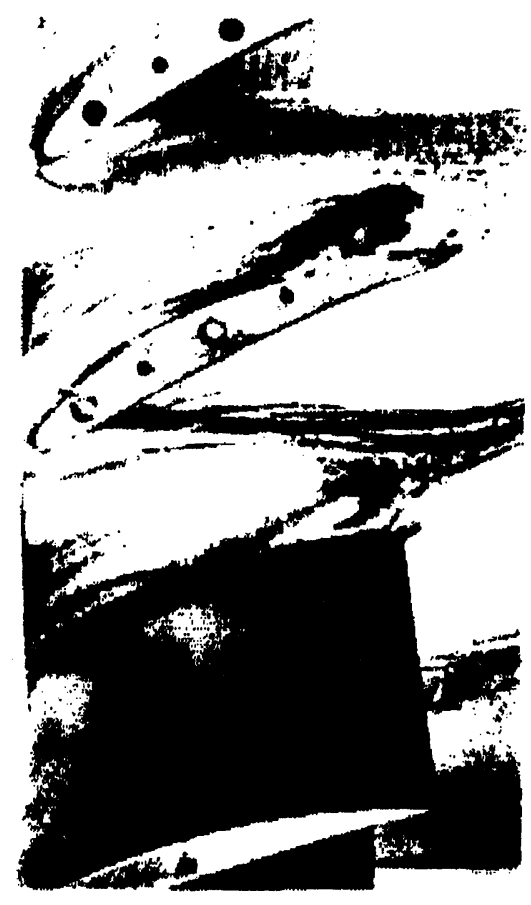

With Rotor

FIGURE 5 Hub and blade suction side flow visualization $\left(\alpha_{2}=44.2^{\circ}\right)$.

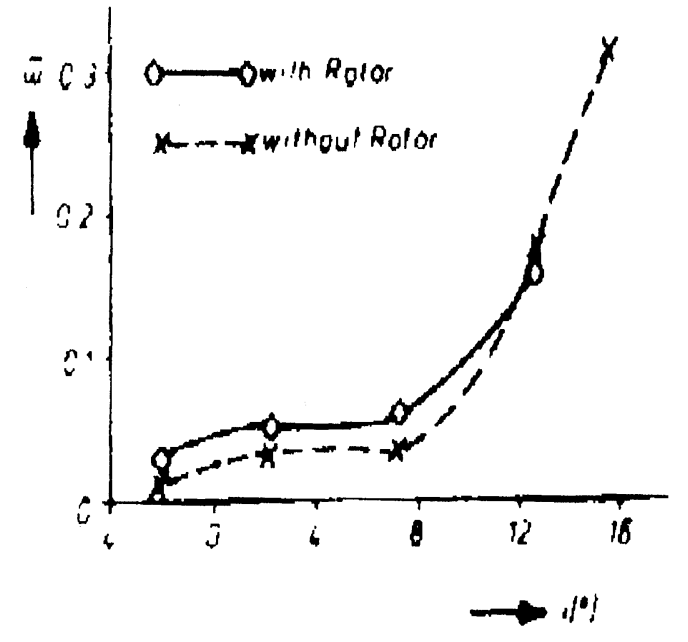

midspan

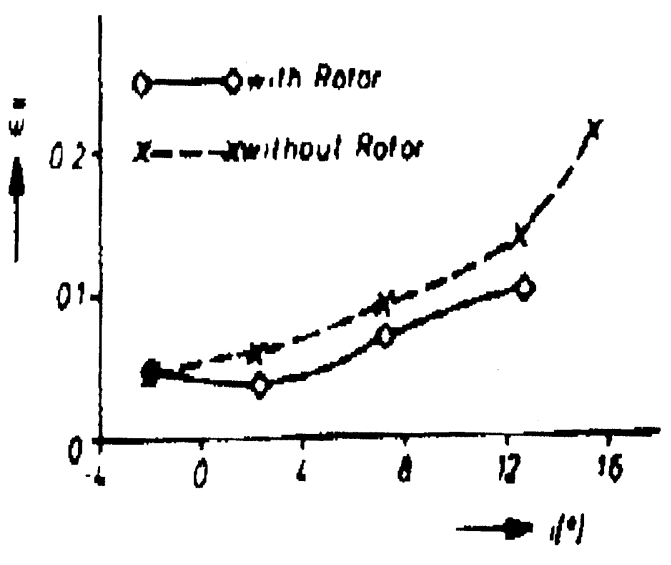

overall

FIGURE 6 Loss distribution with increasing incidence. 
the increase of the profile losses along a small blade height.

These measurements have been supported by further studies on the 3-D boundary layer behaviour and flow field. Due to the complete documentation of data this test case served various authors as validation of their computation codes (Gallus et al., 1990; Lücke et al., 1995; Melake, 1995).

\section{ROTOR-STATOR INTERACTION IN A HIGH SPEED AXIAL-FLOW COMPRESSOR}

The research machine is a single-stage axial-flow compressor with an inlet guide vane row as shown in Fig. 7. The main design parameters of the compressor are listed in Table I.

The objective of the project was to study unsteady flow effects in a high speed compressor. Therefore, the compressor was equipped with various unsteady flow measuring techniques.

The three-dimensional flow field at rotor inlet and outlet was determined with 3-D hot-wire probes. For the unsteady total pressure field downstream of the rotor a probe with a single Kulite type (XB-X-062) semiconductor pressure transducer mounted under a pneumatic tube was used. These probe measurements were taken at midspacing of IGV and stator, respectively. The unsteady pressure at the casing above the rotor-blade tips was detected by a single Kulite (XCQ-062) pressure transducer at 21 axial positions spaced $3.5 \mathrm{~mm}$. To investigate the unsteady transition process of the periodically disturbed profile boundary layers on the suction sides of IGV and stator blades glue-on hot films were used. The IGV and stator blades were in addition provided with semiconductor transducers to measure the unsteady blade pressure distribution. Detailed information on data acquisition and data reduction can be taken from Gallus et al. (1995).

In the following essential results from these investigations with respect to rotor-stator interaction shall be presented. To start with, the tip clearance measurements revealed strong tip clearance flow as is shown in Figs. 8 and 9. Figure 8 represents the pressure distribution above the rotor (ensemble

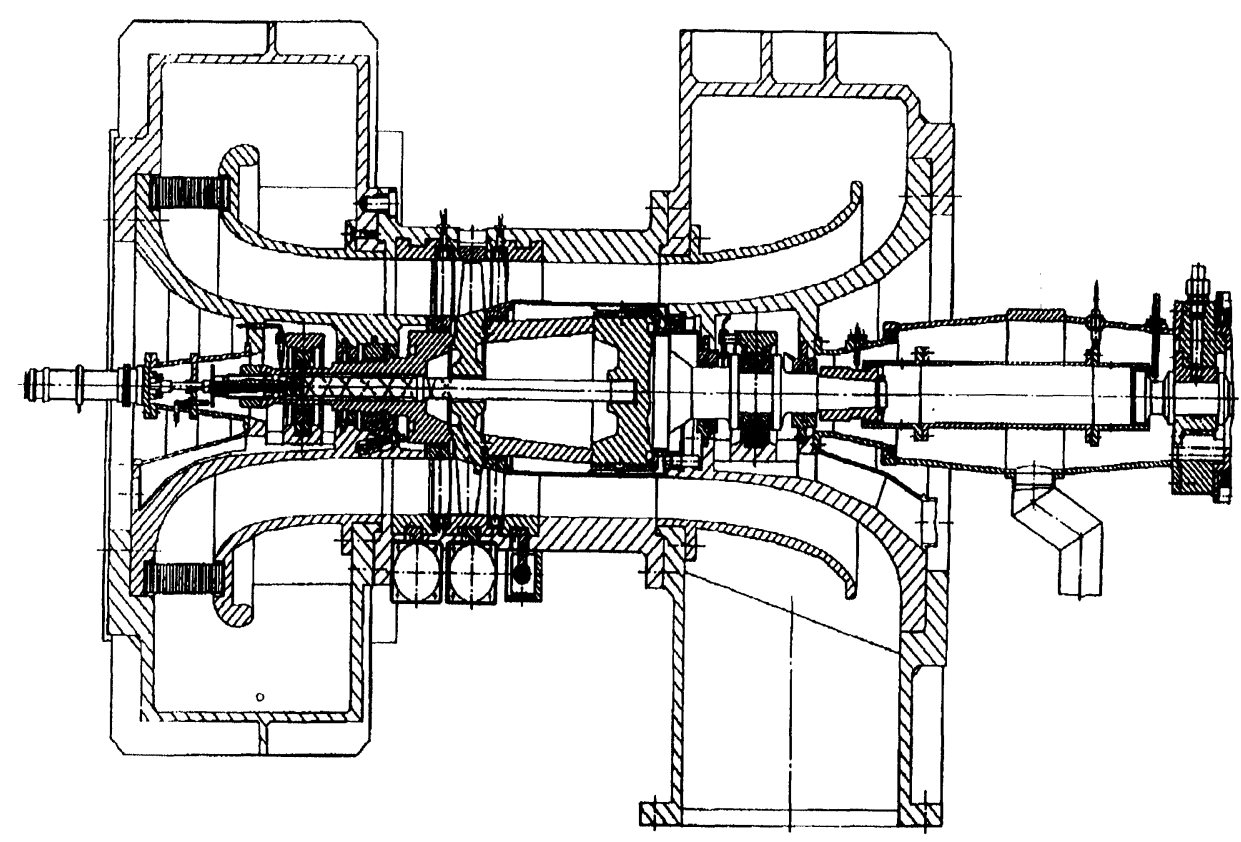

FIGURE 7 Cross-section of the research compressor. 
TABLE I Design parameters of the compressor

\begin{tabular}{llcc}
\hline Nominal speed & $17,000 \mathrm{rpm}$ & & \\
Total pressure ratio & 1.3 & & \\
Design corrected mass flow & $13.4 \mathrm{~kg} / \mathrm{s}$ & & \\
Rotor tip speed & $345 \mathrm{~m} / \mathrm{s}$ & & \\
Tip diameter & $387 \mathrm{~mm}$ & & Stator \\
\hline & IGV & Rotor & 40 \\
\hline Number of blades & 38 & 25 & 1.0 \\
Spacing/chord ratio (tip) & 1.0 & 1.0 & 2.4 \\
Aspect ratio & 2.7 & 1.7 & \\
\hline
\end{tabular}
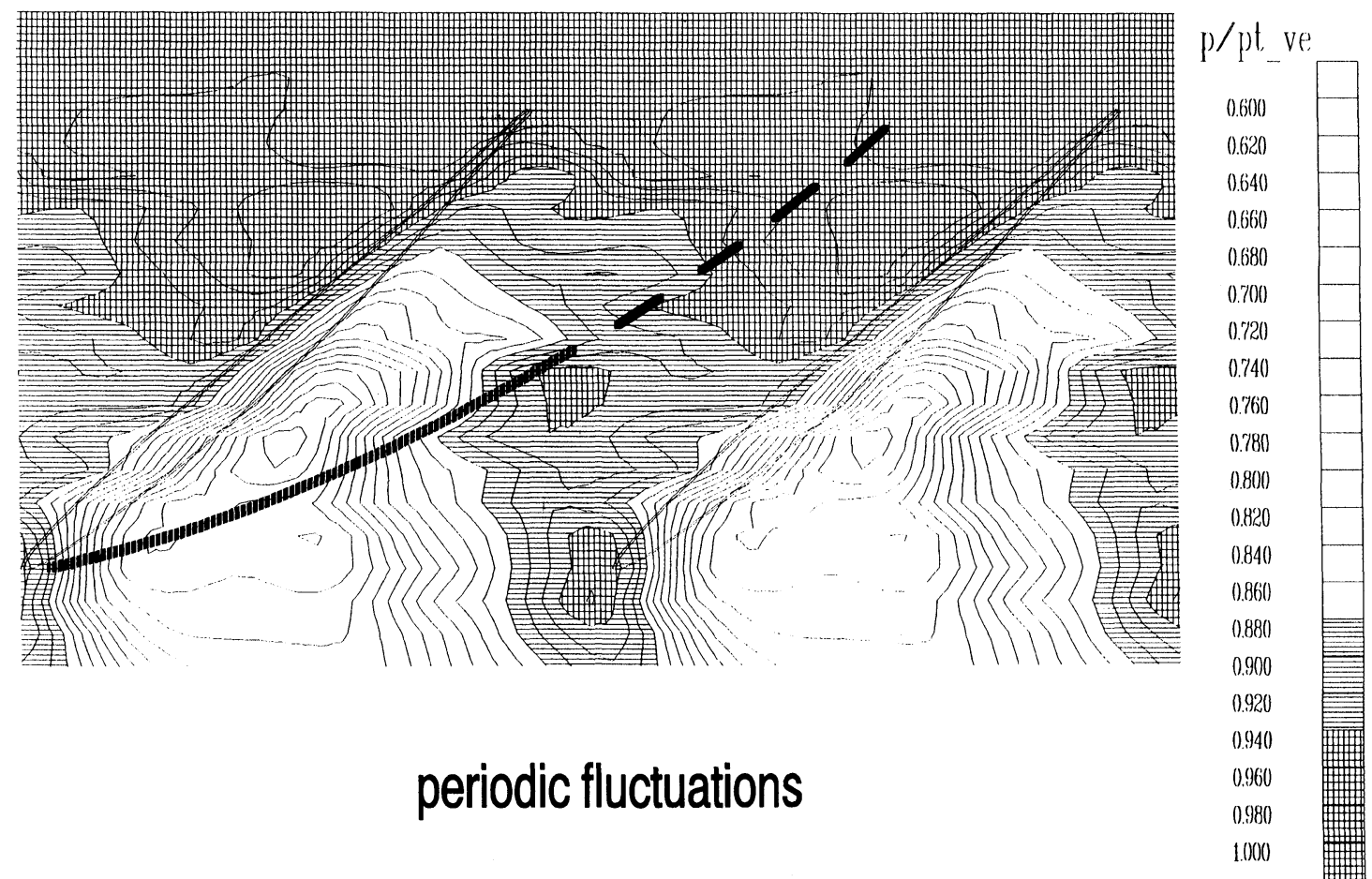

FIGURE 8 Unsteady pressure distribution above the rotor (ensemble-average data).

averaged data) whereas Fig. 9 shows the RMS data. Due to the strong interaction of tip leakage flow and main flow in the tip region the pressure minimum (see Fig. 8) is no longer at the blade suction side surface and the leakage flow vortex is strongly directed to the pressure side of the neighbouring blade. The concentration of high RMS data indicates the location of very intensive interaction of leakage flow and main flow. The strength of the tip leakage vortex can also be detected by hot-wire measurements of the secondary flow distribution downstream of the rotor exit as is shown in Fig. 10.

A very interesting information can be derived from the unsteady pressure distribution measurement at midspan on the suction sides of IGV and stator shown in Fig. 11. The unsteady pressure distributions are plotted in the same scale. Thus, it 


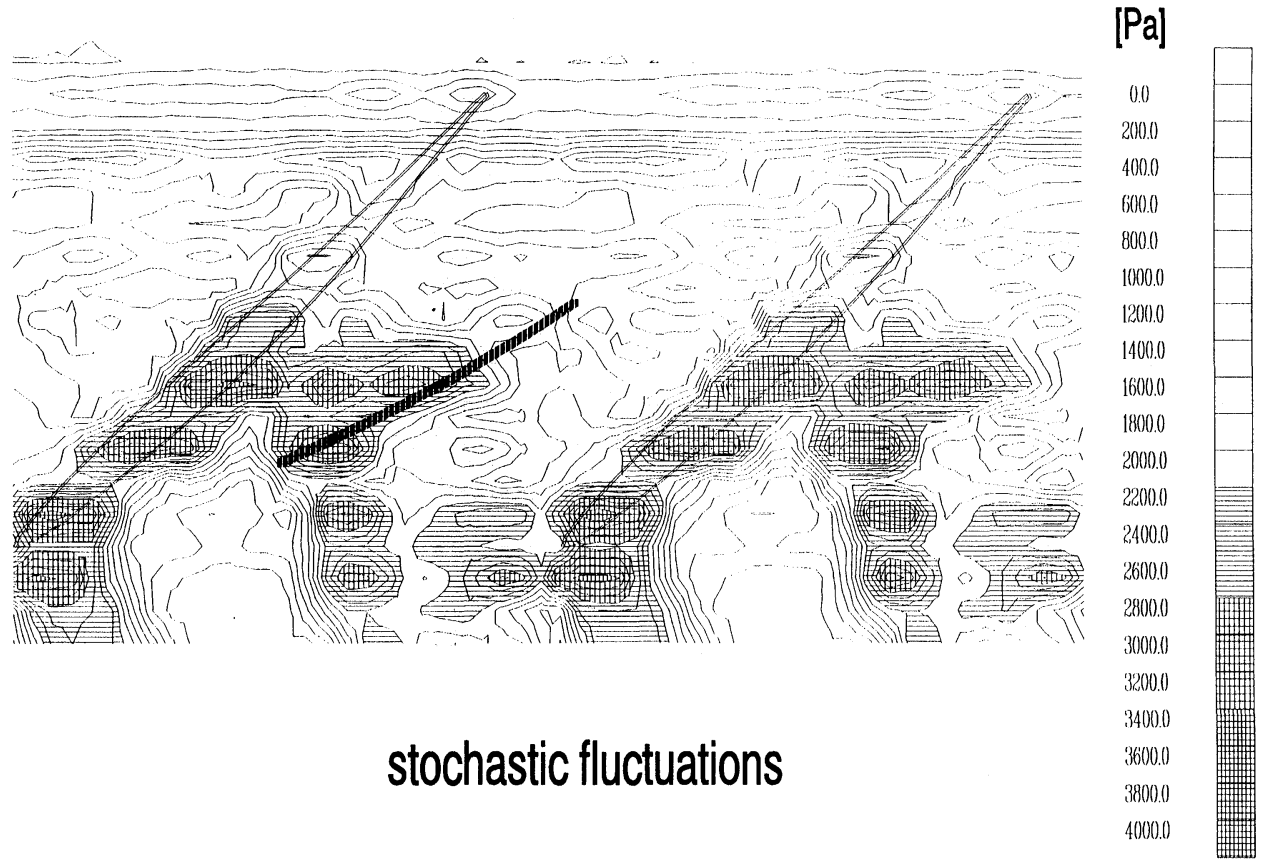

FIGURE 9 Unsteady pressure distribution above the rotor (rms data).

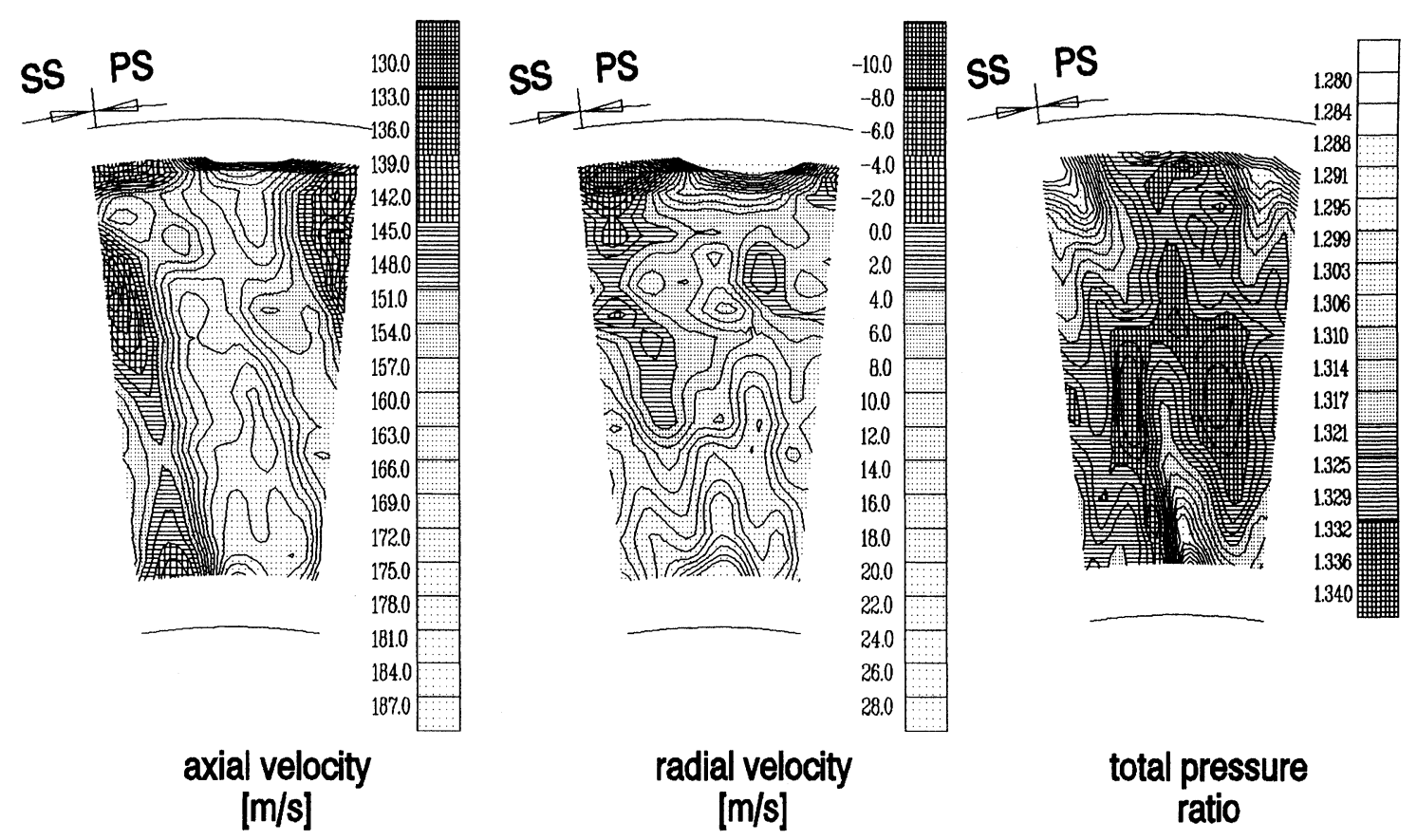

FIGURE 10 Time dependent development at rotor exit (50\% spacing stator, absolute frame). 
IGV, 50\% span, SS
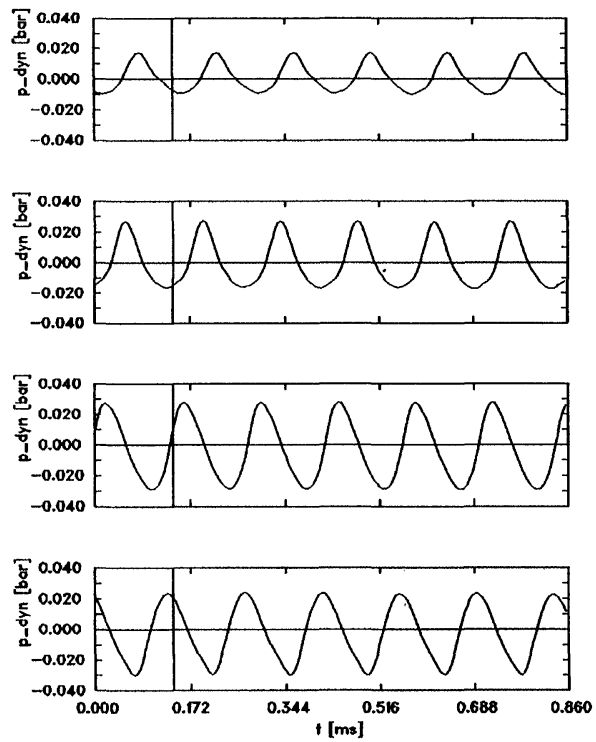

Stator, $50 \%$ span, SS
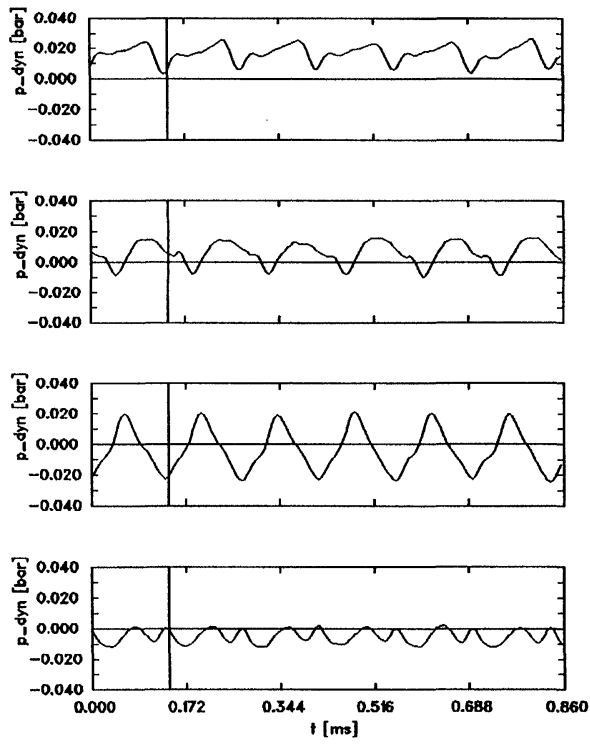

FIGURE 11 Unsteady pressure distribution at midspan on suction side of IGV and stator.

is obvious that the potential-theoretic upstream interaction of the rotor on the IGV vanes is much stronger than the downstream interaction on the stator blades composed of potential-theoretic and wake interaction. Similar effects have been mentioned already in the introduction of this paper.

Along with the before described pressure fluctuation on the blade surfaces of IGV and stator the study of the boundary layer behaviour is most important with respect to the effect of unsteadiness on the position and axial extent of boundary layer transition as well as its influence on loss development. Figures 12 and 13 allow to compare the boundary layer development at midspan on the suction sides of IGV and stator blades, respectively. Comparing first the ensemble averaged data in the left columns of both figures we recognize again that also the glue-on hot-wire films show much stronger values of the real time data upstream of the rotor on the IGV surface than downstream on the stator. The frequency spectra are plotted in the middle column and show in agreement with the ensemble averaged data quite another boundary layer behaviour for the IGV
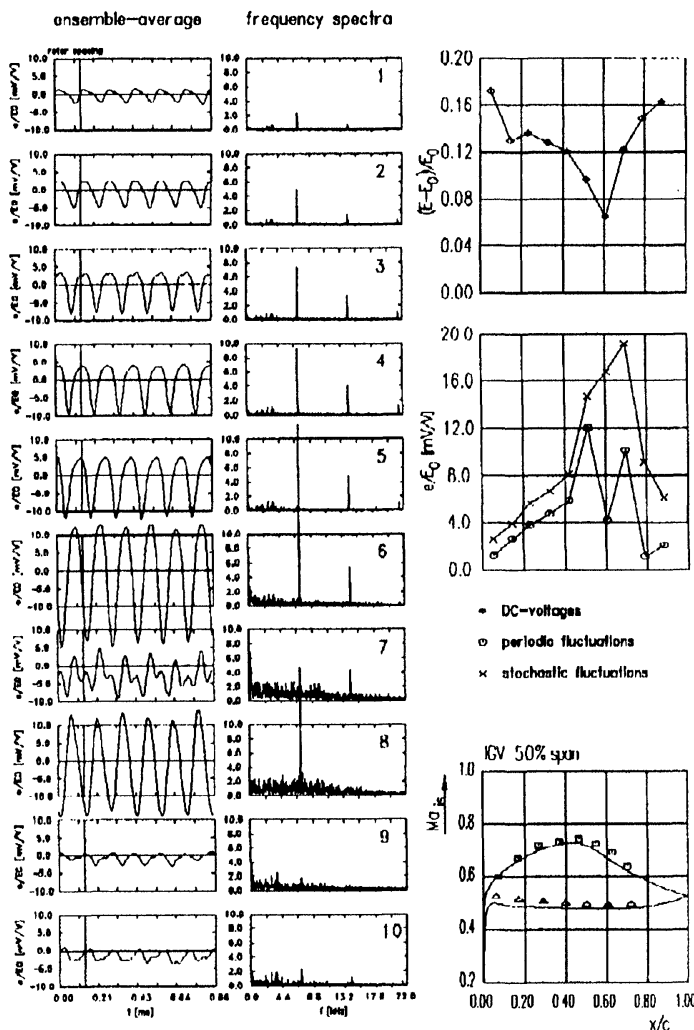

DC-roltoper

- perlodio thecluetlon

$x$ atochoalic thetuations

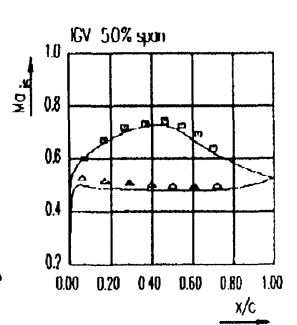

FIGURE 12 Boundary layer development at midspan on suction side of IGV. 


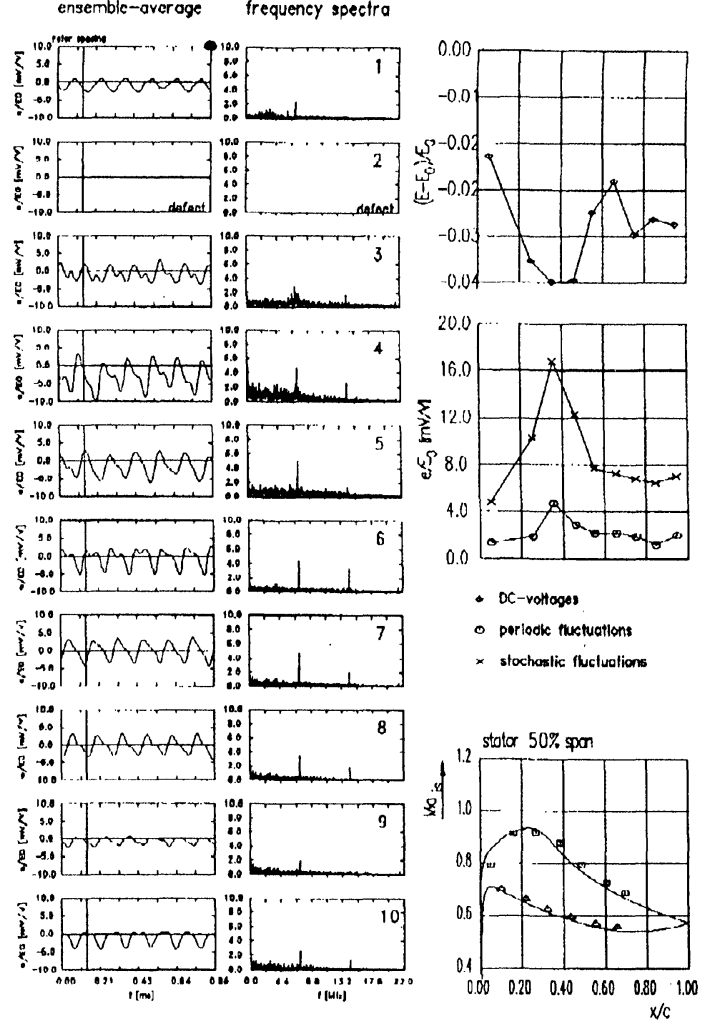

FIGURE 13 Boundary layer development at midspan on suction side of stator.

than for the stator. Figure 12 shows an increase of the amplitudes of the ensemble averaged data as well as frequency spectra up to sensor 6 immediately followed by a relative minimum at sensor 7 and a relative maximum shortly downstream at sensor 8 . Figures 12 and 13 describe from the left to the right the periodic ensemble average signals, the affiliated frequency spectra and the time averaged values. Here, the normalized dc-voltages and the time-averaged random and periodic fluctuations are plotted over the associated steady pressure distribution. For a general impression of the transition process in the boundary layer the plots have to be viewed side by side.

During the acceleration the dc-voltages go down continuously until sensor 7 lying slightly behind the suction side pressure minimum. In the front part the boundary layer is laminar. Before the pressure minimum is reached the random fluctuations start to increase rapidly to their maximum at about $70 \%$ chord (sensor 8 ) which can also be seen in the frequency spectra. The boundary layer decelerates, grows instable and thus more sensitive to fluctuations in the core flow. Parallel herewith the distribution of the time-averaged periodic fluctuations got a minimum at sensor 7 between two maxima. Referring to Schröder (1989) and Hourmouziadis et al. (1986) this is characteristic for a transition via a separation bubble. The bubble oscillates with blade passing frequency and its extension depends on it (Dong and Cumpsty, 1989). Both the beginning and the end of transition differs in time with rotor-stator position. The whole transition takes place over ca. $30 \%$ chord. Not until sensor 9 the boundary layer is completely turbulent.

The profile boundary layer of the stator is influenced by the rotor wakes (Fig. 13). The amplitudes are smaller in comparison with the IGV. The ensemble-average-signal of sensor 3 indicates that there the flow is already affected by the transition although the normalized dc-voltages reach their minimum behind the measured steady pressure minimum at sensor 4 . A similar second maximum was observed by Dong and Cumpsty (1989). It is caused by the faster travelling wakes in the free stream. Sensor 4, where in contrast to the IGV both maxima of random and periodic fluctuations are situated, is lying in the transition zone all the time. A so-called "bypass"-transition takes place. The whole transition is stretched until sensor 6 . This is more than $30 \%$ chord.

\section{STATOR-ROTOR-STATOR INTERACTION IN AN AXIAL-FLOW TURBINE AND ITS INFLUENCE ON LOSS MECHANISMS}

Detailed measurements have been performed in a subsonic, axial flow turbine stage to investigate the structure of the secondary flow field and the loss 


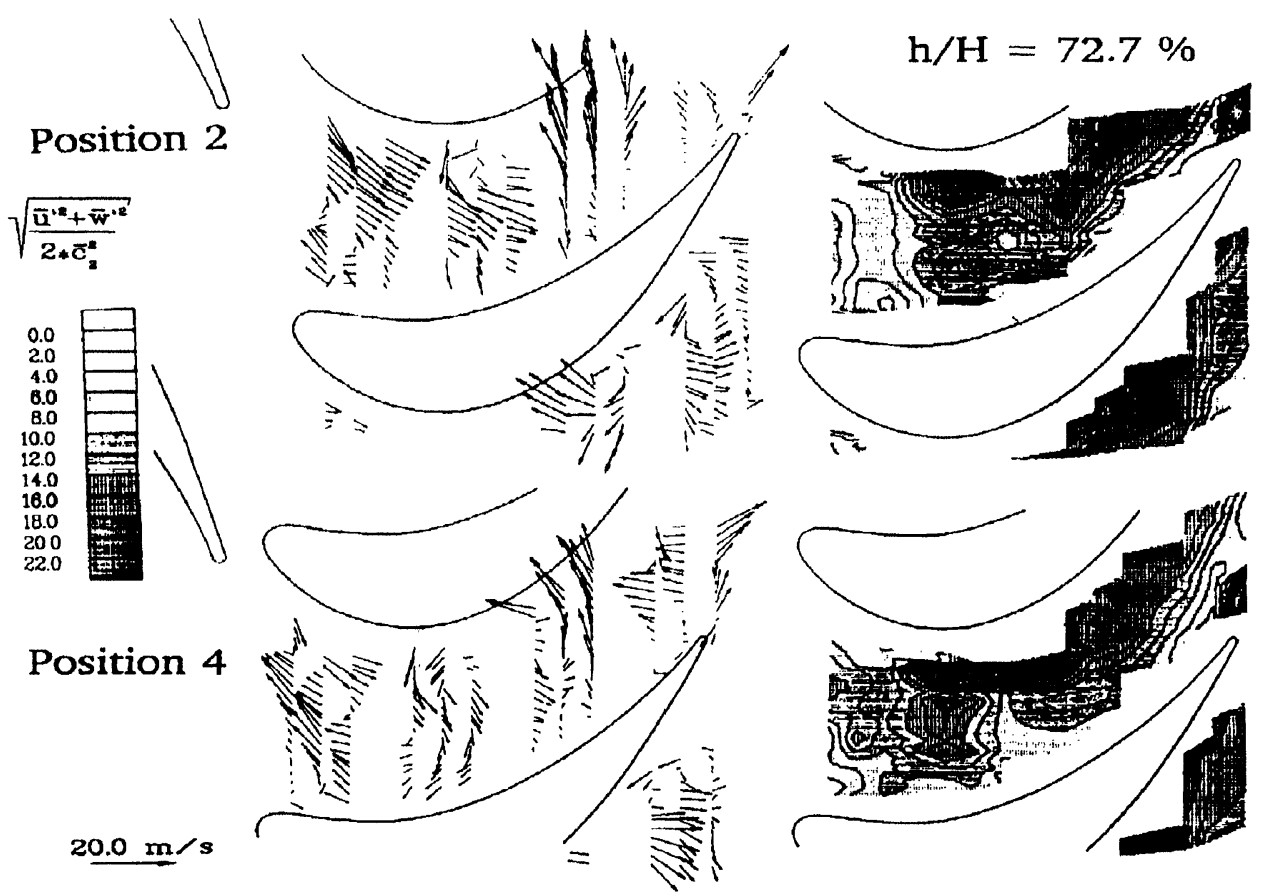

FIGURE 14 Secondary flow and turbulence intensity in the turbine rotor (at $72.7 \%$ span).

generation (Zeschky and Gallus, 1993). The data include the static pressure distribution on rotor blade passage surfaces and radial-circumferential measurements of the rotor exit flow field using three-dimensional hot-wire and pneumatic probes. The flow field at the rotor outlet is derived from unsteady hot-wire measurements with high temporal and spacial resolution. The above-mentioned paper presents the formation of the tip clearance vortex and passage vortices which are strongly influenced by the spanwise nonuniform stator outlet flow. The experimental results of the unsteady flow velocity and turbulence measurements demonstrate the influence of the periodic stator wakes onto the rotor flow.

Figure 14 shows the cross flow patterns inside the rotor blade passages. The arrows represent the difference between the local velocity vector and the relative velocity field in the rotor. According to the reduced frequency two stator wakes are simultaneously present in each rotor passage. Due to the cut stator wakes and secondary vortices from the stator the turbulence level is increased. Similar results were obtained by Binder (1985). The higher acceleration at the blade suction sides causes a distortion of the stator wakes. Nevertheless, cross flow components are still observed close to the trailing edge and downstream of the rotor.

The relative flow angles and turbulence intensities inside the rotor passage in snap shots for four rotor-stator positions are shown in Fig. 15. The distributions show the angle and turbulence conditions over the blade height at an axial position of $x / b_{\mathrm{p}}=13.9 \%$. At rotor position 2 higher flow angles occur in the corner between pressure side and casing representing a cross flow towards the suction side. The reasons for this are the lower velocity and the underturning in the high loss area of the stator exit flow. Turbulence spots associated with the stator loss cores appear. At position 4 the stator wake is visible over the entire span with strong distortions at $h / H=15$ and $h / H=85 \%$. Due 

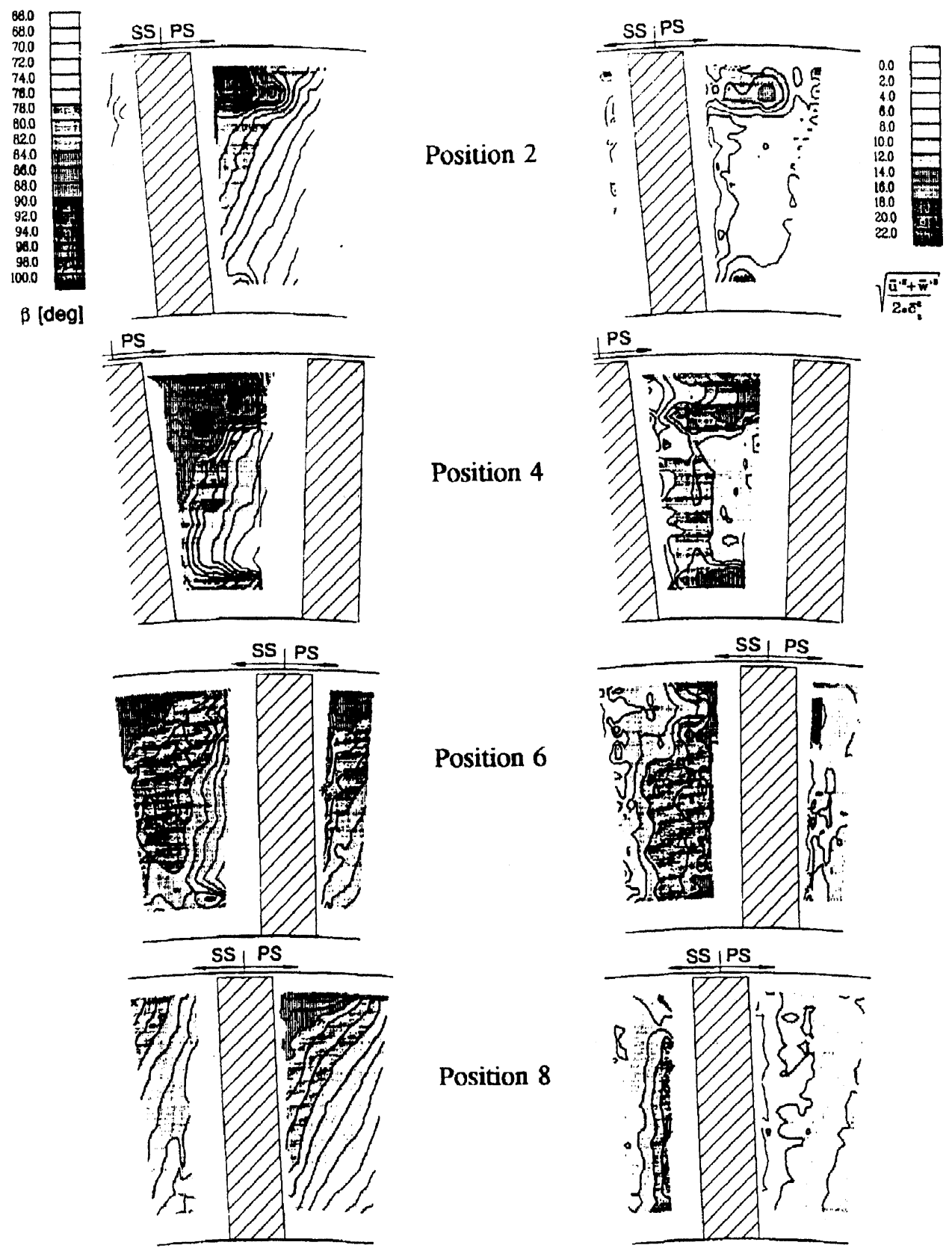

FIGURE 15 Flow angle distribution and turbulence intensity inside the rotor passage for four different stator-rotor positions.

to the higher absolute flow angles the wake in the tip region and the loss cores are passing earlier. At position six the flow angles decrease after the passing of the wake. Position 8 shows the undis- turbed flow field with a reduced turbulence level. The blade to blade gradient is caused by the different turning and acceleration at the pressure and suction side. 
The measurements show that the rotor secondary flow is mainly caused by the radial nonuniform stator exit flow and the periodically unsteady transport of the stator wakes through the rotor passages. The endwall boundary layer at the rotor inlet are very thin which is a result of the transport mechanisms and the acceleration in the stator. Therefore, the highest overturning does not occur close to the side walls but at $15 \%$ and $85 \%$ span.

\section{CONCLUSIONS}

The measurements of the unsteady three-dimensional flow fields in compressors and turbines demonstrated quite different behaviour of the secondary flow and loss production. Inside the turbine stator strong passage vortices are generated by the endwall boundary layers. The low momentum fluid of the boundary layers is accumulated inside these two vortices. Therefore, the endwall boundary layers at the rotor inlet are very thin. They contribute only in a small scale to the rotor secondary flow.

The secondary flow field in a compressor blade row is much more complicated. The endwall boundary layers do not have the major and dominant influence as it was observed in the turbine tests, since the pressure gradient from blade to blade is lower. The intensity of the secondary flows due to leakage, profile boundary layer centrifugation, nonuniform blade circulation, is of the same magnitude. On the other hand flow separations like corner stall and rotor blade tip stall are present. Furthermore, the wake decay takes place in an adverse pressure field so that higher turbulence levels are generated inside the wake.

The measuring results demonstrated that the total pressure losses of compressor cascades with low aspect ratios $(<1.0)$ decreased in unsteady flow compared to those obtained in an undisturbed flow field (without rotor). This tendency has been observed at various incidence angles. Although the profile losses at midspan increase due to the earlier onset of boundary layer transition in the case with rotor, the overall losses decrease. This can be related to the significant loss reduction due to a smaller hub corner stall region. Intensive turbulent mixing in the wakes is believed to diminish the hub corner stall.

Comparing the influence of the rotor-stator interaction in compressor and turbine flow completely different mechanisms of loss re-distribution can be observed. In the turbine rotor a distinct shift of the loss cores occurring downstream of the stator towards midspan can be observed. Therefore, the dominant mixing effect in the turbine stage is caused by the intensive secondary flow.

\section{References}

Binder, A. (1985) Turbulence production due to secondary vortex cutting in a turbine rotor, Journal of Engineering for Gas Turbine and Power, 107.

Dong, Y. and Cumpsty, N.A. (1989) Compressor blade boundary layers, Part I and Part II, ASME 89-GT-50, ASME 89-GT-51.

Gallus, H.E., Grollius, H. and Lambertz, J. (1982) The influence of blade number ratio and blade row spacing on axial-flowcompressor stator blade dynamic load and stage sound pressure level, Journal of Engineering for Power, 104, 633-641.

Gallus, H.E., Schulz, H.D. and Hah, C. (1990) Experimental and numerical investigation of three-dimensional viscous flows and vortex motion inside an annular compressor blade row, ASME Paper 90-GT-155.

Gallus, H.E., Pieper, S., Schulte, J. and Hoynacki, A. (1995) Unsteady flow behaviour in a high speed axial-flow compressor, International SYMKOM '95, Lodz, Polen.

Henderson, R.W. (1972) The unsteady response of an axial-flow turbomachine to an upstream disturbance, Ph.D. Thesis, University of Cambridge.

Hourmouziadis, J., Buckl, F. and Bergmann, P. (1986) The development of the profile boundary layer in a turbine environment, ASME 86-GT-244.

Lienhart, W. (1973) Berechnung der instationären Strömung durch gegeneinander bewegte Schaufelgitter und der instationären Schaufelkräfte, VDI-Bericht No. 193.

Lücke, J., Benetschik, H., Lohmann, A. and Gallus, H.E. (1995) Numerical investigation of three-dimensional separated flows inside an annular compressor cascade, International SYMKOM '95, Lodz, Polen.

Melake, A. (1995) Numerische Simulation der Strömung im radialen Schaufelspalt axialer Turbomaschinen, Dissertation RWTH Aachen.

Schulz, H.D. and Gallus, H.E. (1988) Experimental investigation of the three-dimensional flow in an annular compressor cascade, Journal of Turbomachinery, 110, 467-478.

Schulz, H.D., Gallus, H.E. and Lakshminarayana, B. (1990) Three-dimensional separated flow field in the endwall region of an annular compressor cascade in the presence of rotorstator interaction. Part I: "Quasi-steady flow field and comparison with steady-state data". Part II: "Unsteady flow and pressure field", Journal of Turbomachinery, 110. 
Schröder, Th. (1989) Measurements with hot-film probes and surface-mounted hot-film gauges in a multistage low-pressure-turbine, Proceedings European Propulsion Forum: Modern Techniques and Developments in Engine and Component Testing, Bath, UK, pp. 15.1-15.27.
Zeschky, J. and Gallus, H.E. (1993) Effects of stator wakes and spanwise nonuniform inlet conditions on the rotor flow of an axial turbine stage, Transaction of the ASME, 115. 


\section{ait \\ ENERGY MATERIALS}

M A N E Y publishing

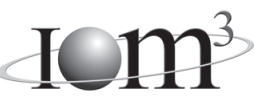

\section{Materials Science \& Engineering for Energy Systems}

Maney Publishing on behalf of the Institute of Materials, Minerals and Mining

The Institute of Materials, Minerals \& Mining

Economic and environmental factors are creating ever greater pressures for the efficient generation, transmission and use of energy. Materials developments are crucial to progress in all these areas: to innovation in design; to extending lifetime and maintenance intervals; and to successful operation in more demanding environments. Drawing together the broad community with interests in these areas, Energy Materials addresses materials needs in future energy generation, transmission, utilisation, conservation and storage. The journal covers thermal generation and gas turbines; renewable power (wind, wave, tidal, hydro, solar and geothermal); fuel cells (low and high temperature); materials issues relevant to biomass and biotechnology; nuclear power generation (fission and fusion); hydrogen generation and storage in the context of the 'hydrogen economy'; and the transmission and storage of the energy produced.

As well as publishing high-quality peer-reviewed research, Energy Materials promotes discussion of issues common to all sectors, through commissioned reviews and commentaries. The journal includes coverage of energy economics and policy, and broader social issues, since the political and legislative context influence research and investment decisions.

\section{CALL FOR PAPERS}

Contributions to the journal should be submitted online at http://ema.edmgr.com

To view the Notes for Contributors please visit: www.maney.co.uk/journals/notes/ema

Upon publication in 2006, this journal will be available via the Ingenta Connect journals service. To view free sample content online visit: www.ingentaconnect.com/content/maney

For further information please contact:

Maney Publishing UK

Tel: +44 (0)113 2497481 Fax: +44 (0)1132486983 Email: subscriptions@maney.co.uk

or

Maney Publishing North America

Tel (toll free): 8662975154 Fax: 6173546875 Email: maney@maneyusa.com

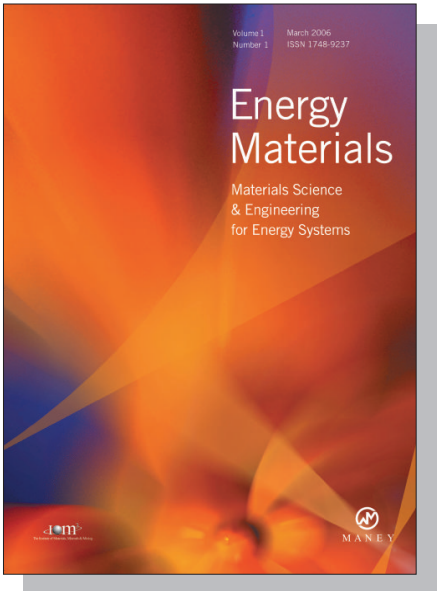

EDITORS

Dr Fujio Abe

NIMS, Japan

Dr John Hald, IPL-MPT, Technical University of Denmark, Denmark

Dr R Viswanathan, EPRI, USA

\section{SUBSCRIPTION INFORMATION}

Volume 1 (2006), 4 issues per year

Print ISSN: 1748-9237 Online ISSN: 1748-9245

Individual rate: $£ 76.00 / U S \$ 141.00$

Institutional rate: $£ 235.00 /$ US $\$ 435.00$

Online-only institutional rate: $£ 199.00 / U S \$ 367.00$

For special $\mathrm{IOM}^{3}$ member rates please email

subscriptions@maney.co.uk

\section{For further information or to subscribe online please visit www.maney.co.uk}



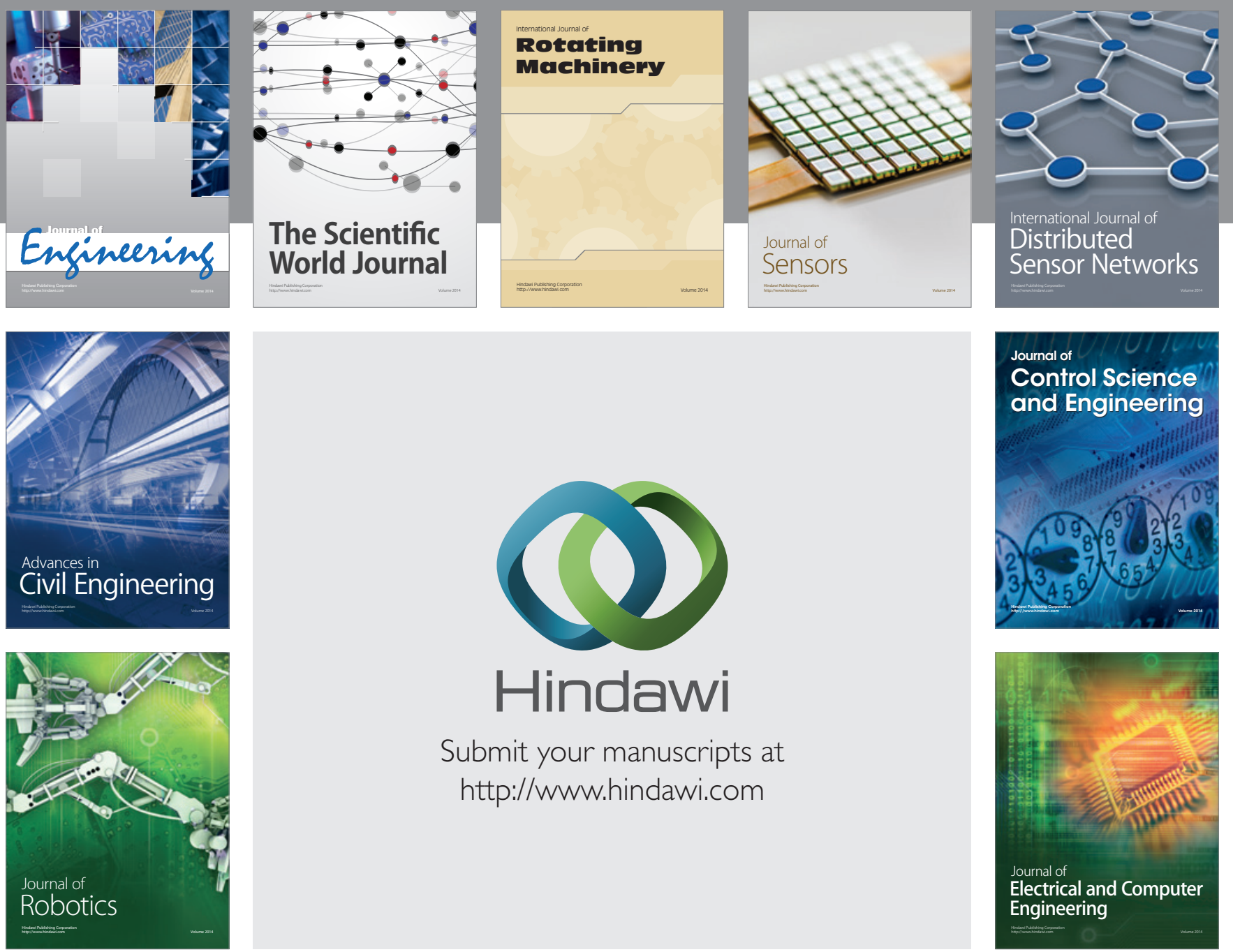

Submit your manuscripts at

http://www.hindawi.com
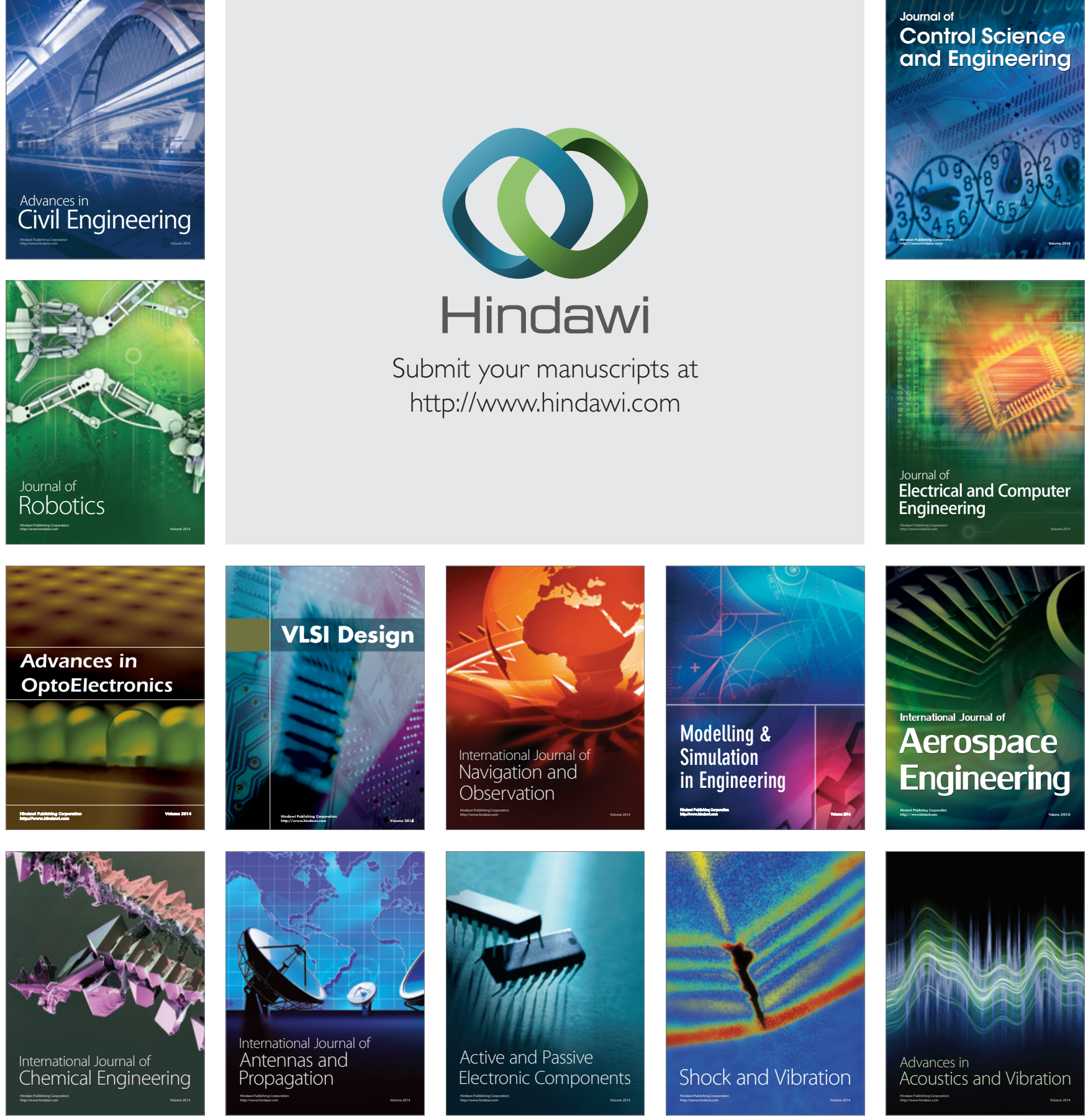